$11 \%$ ) e um condrossarcoma em articulação têmporo-mandibular $(5,5 \%)$. A idade média dos animais acometidos foi de 11,8 anos, com idade máxima de 18 anos em um caso de adenocarcinoma e idade mínima de 7 anos em outro caso de adenocarcinoma. Os SRD foram os animais mais acometidos (13 casos, $72,22 \%$ ), seguidos pelo Siamês (3 casos, $16,66 \%$ ), o Persa e o Angorá (cada um responsável por 5,5\% dos casos). Em todos os casos, os SRD foram os mais acometidos. $66,66 \%$ dos gatos eram machos e $33, \%$ eram fêmeas e, em cada tipo de neoplasia, individualmente, notou-se significativa ocorrência em machos. Neste estudo pudemos observar uma alta prevalência de neoformações na cavidade oral de animais sem raça definida, o que pode ser explicado pela maior quantidade destes animais em nosso país. A ocorrência elevada de CCE já era esperada, ainda que neste trabalho tenhamos observado um taxa menor do que as relatadas em literatura estrangeira. O fibrossarcoma, segundo tumor maligno mais freqüente entre os gatos, não foi detectado neste trabalho, sendo que sua posição foi ocupada pelo adenocarcinoma. Outra observação importante deve ser feita em relação à predisposição sexual. Neste estudo pudemos perceber uma ocorrência de tumores, benignos ou malignos, bastante alta em machos, o que pode sugerir uma predisposição sexual. A faixa de idade destes animais acometidos é bastante alta, não sendo encontrado nenhum caso em animais com menos de 7 anos de idade. Os animais brasileiros têm apresentado expectativa de vida cada vez mais alta o que, em última análise, pode estar predispondo-os a maior ocorrência de neoplasias, sejam elas benignas ou de caráter maligno.

\title{
77 - Mixossarcoma em cavidade abdominal em Boxer. Relato de caso
}

1- Docente da Pontifícia Universidade Católica, Campus de Poços de Caldas, Poços de Caldas-MG e Docente do Centro Regional de Ensino Veterinário de Espírito Santo do Pinhal, Espírito Santo do Pinhal-SP. Aluna do curso de pós graduação (nivel doutorado) em Cirurgia Veterinária da Universidade Estadual Paulista, Campus de Jaboticabal, Jaboticabal-SP

2- Docente do Centro Regional de Ensino Veterinário de Espírito Santo do Pinhal, Espírito Santo do Pinhal -SP

O mixossarcoma é uma neoplasia rara observada em cães e gatos, originada de fibroblastos alterados que produzem quantidade excessiva de mucina. Os animais acometidos são geralmente adultos ou idosos e não há predisposição racial ou sexual. Microscopicamente o mixossarcoma é diferenciado do fibrossarcoma por apresentar uma abundante matriz mucinosa intercelular. O tumor apresenta característica infiltrativa com bordas pouco definidas. Os mixossarcomas variam desde massas sésseis ou pedunculadas pequenas a grandes, que incluem desde massas globulares duras, mosqueadas com hemorragias, até lesões papilares moles e translúcidas, de aspecto gelatinoso. Apesar de ser uma neoplasia maligna, o mixossarcoma apresenta um baixo grau de malignidade com raras ocorrências de metástase, no entanto, exibe freqüentemente recorrência após excisão cirúrgica. $\mathrm{O}$ tratamento de escolha é a exérese cirúrgica e não existem relatos de sucesso com radioterapia ou quimioterapia. Foi atendida uma cadela da raça boxer, intacta, com 3 anos de idade no Hospital Veterinário do Curso de Medicina Veterinária do Centro Regional de Ensino Universitário de Espírito Santo de Pinhal (CREUPI). A queixa principal da proprietária era um aumento de volume abdominal progressivo com evolução de 8 meses. Foram realizados exames radiográfico $\mathrm{e}$ ultrassonográfico com laudos de presença de massa de aproximadamente $25 \mathrm{~cm}$ de diâmetro em cavidade abdominal aparentemente sem relação a outros órgàos cavitários. Os valores do hemograma, uréia e alamino amino transferase encontravam-se dentro dos parâmetros normais. Optou-se pela laparotomia exploratória e durante a cirurgia foi encontrada a massa tumoral aderida ao mesentério. A massa foi retirada juntamente com $25 \mathrm{~cm}$ de alça intestinal devido a hipóxia tecidual, pois a vascularização da neoplasia era a mesma do intestino delgado. Foi realizada a entero-anastomose e omentopexia. O aspecto macroscópico era de uma estrutura com $25 \mathrm{~cm}$ de diâmetro localizada no mesentério de aspecto multilobulado, 
coloração avermelhada com áreas claras alternando com áreas hemorrágicas. A consistência era macia e o tumor pesava $2,3 \mathrm{~kg}$, ao corte houve exsudação de liquido vermelho claro e a massa apresentava um aspecto gelatinoso. O laudo histopatológico com coloração hematoxilina-eosina revelou células com formato predominantemente estrelado distribuídas em um abundante estroma mucinoso fracamente basofilico com pequena quantidade de fibras colágenas, diagnosticando o mixossarcoma. A cadela recuperou-se bem não apresentando nenhuma alteração durante o periodo pós operatório imediato e após 15 meses nào havia ocorrido recidiva. $\mathrm{O}$ relato deste caso ocorreu devido a natureza rara da neoplasia, além de seu tamanho, o qual não causava nenhuma alteração no trànsito intestinal.

Carvalho Filho, A.S.? Aptekmann, K.P. ${ }^{2} ;$ Schwartz, D.S. ${ }^{3}$; Calderón, C. ${ }^{\text {; }}$ Amorim, R.L. ${ }^{2}$ Rodrigues, M.M.P. ${ }^{2}$

\section{8 - Hemangiossarcoma cardíaco em cão. Relato de dois casos}

1- Pós-graduando do Departamento de Clínica Veterinária da Faculdade de Medicina Veterinária da Universidade Estadual Paulista, Campus de Botucatu, Botucatu-SP

2 - Residente do Departamento de Clínica Veterinária da Faculdade de Medicina Veterinária da Universidade Estadual Paulista, Campus de Botucatu, Botucatu-SP

3 - Professora Assessora Doutora do Departamento de Clínica Veterinária da Faculdade de Medicina Veterinária da Universidade Estadual Paulista, Campus de Botucatu, Botucatu-SP

O hemangiossarcoma é uma neoplasia maligna composta por células endoteliais que desenvolve-se mais frequentemente em cães do que em outras espécies. Estudos demonstram que é a neoplasia cardiaca mais comum e pode se desenvolver, mais comumente, em coração, baço, figado, músculo, tecido subcutâneo, pele e ossos. Geralmente, os tumores cardíacos primários em cães envolvem o lado direito do coração, especialmente o átrio direito. Em 01/08/02 foi atendido um canino, Boxer, macho, com 10 anos de idade e queixa de três episódios de síncope no dia anterior a consulta. Ao exame clínico o animal apresentava apatia, prostraçào, anorexia, emagrecimento progressivo, emese, aumento de linfonodos submandibulares e popliteos, hipotermia, bradicardia $(30 \mathrm{bpm})$, sopro sistólico com grau III/VI em foco de válvula mitral. $\mathrm{O}$ eletrocardiograma indicou a presença de bradicardia, bloqueio-átrio ventricular completo com complexos de escape ventricular e periodos intermitentes de ritmo idioventricular acelerado. A radiografia torácica indicou a presença de massa em região de átrio direito com desvio dorsal de traquéia na posição látero-lateral. O hemograma apresentava anemia normocitica normocrômica, leucocitose com neutrofilia e desvio à esquerda, monocitose, trombocitopenia e o perfil bioquímico revelava discreto aumento da fosfatase alcalina. A hemogasometria indicou a presença de acidose metabólica compensada e hipercaliemia. Foi realizada fluidoterapia com glicose 5 $\%$ com correçào do distúrbio ácido-básico e eletrolítico. A aplicação de atropina e aminofilina foram ineficazes na tentativa de aumentar da frequência cardiaca. $\mathrm{O}$ animal foi a óbito durante a introduçào do marcapasso cardíaco externo. Na necrópsia o animal apresentava um tumor em base de coração direito que foi diagnosticado, posteriormente, como hemangiossarcoma por técnicas citológicas e de imunoistoquímicas para vimentina e fator VIII. A técnica imunoistoquímica também mostrou a presença de células neoplásicas infiltradas em miocárdio e tecido de condução que, provavelmente, estavam levando ao bloqueio átrio-ventricular completo. O segundo caso, atendido em $08 / 05 / 03$, tratava-se de um canino, Pastor Alemão, macho, com 10 anos de idade. $\mathrm{O}$ animal apresentava histórico de cansaço, anorexia e dificuldade em se locomover por alteraçào na coluna. Ao exame clínico observou-se dispnéia moderada e abafamento dos sons cardíacos à auscultação. $\mathrm{O}$ hemograma revelou anemia normocítica normocrômica. A radiografia torácica evidenciou um aumento generalizado da silhueta cardiaca, com desvio dorsal da traquéia e padrão pulmonar alveolar em lobo diafragmático. O eletrocardiograma não evidenciou alterações. Foi realizado o exame ecocardiográfico que revelou efusão pericárdica com massa intrapericárdica e tamponamento cardíaco. Foi realizada pericardiocentese com retirada de 1,2 litros de líquido, 